\section{Effect of Orthodontic Bracket Type and Mouthguard Presence on the Stress and Strain during a Frontal Impact}

\author{
Júlio César de Carvalho Alves ${ }^{10}$, Gilberto Antônio Borges ${ }^{10}$, Antheunis \\ Versluis $^{2}{ }^{(1)}$ Carlos José Soares ${ }^{3}{ }^{(1)}$, Crisnicaw Verissimo ${ }^{4}$
}

\author{
'Department of Restorative \\ Dentistry, School of Dentistry, \\ UNIUBE - Universidade de \\ Uberaba, Uberaba, MG, Brazil \\ ${ }^{2}$ Department of Bioscience Research, \\ College of Dentistry, University \\ of Tennessee Health Science \\ Center, Memphis, TN, USA \\ ${ }^{3}$ Department of Operative Dentistry \\ and Dental Materials, School of \\ Dentistry, UFU - Universidade \\ Federal de Uberlândia, MG, Brazil \\ ${ }^{4}$ Department of Oral Rehabilitation, \\ School of Dentistry, UFG \\ - Universidade Federal de \\ Goiás, Goiânia, GO, Brazil \\ Correspondence: Dr. Crisnicaw \\ Veríssimo, Avenida Universitária, \\ Setor Leste Universitário, Sala 3024. \\ 74.605-020 Goiânia, G0, Brasil. \\ Tel: +55-62-3209-6494. e-mail: \\ crisnicaw.verissimo@ufg.br
}

Key Words: mouth guard, biomechanical phenomena, finite element analysis, orthodontics brackets.

\section{Introduction}

Dental and oral facial injuries are common during sports practice (1). Some studies showed that there is a higher risk for dental traumas in patients with malocclusions that are undergoing orthodontic treatment (2). Class II malocclusions with positive overjet are more susceptible to sustain dental injuries because of the maxillary incisor protrusion $(3,4)$. These malocclusions or skeletal deformities are associated and can be classified into two clinically relevant subgroups: A) Anterior projection of the maxillary teeth (Overjet); and B) Relationship of discrepancy between the maxillary bones (maxilla and jaw) (5). Maxillary protrusions are also associated with inadequate or poor lip coverage that also increases the risk for anterior dental trauma. It is reported that an overjet larger than 6 or $7 \mathrm{~mm}$ increases the risk for dental trauma, and when the overjet is more than $6 \mathrm{~mm}$, frequently the consequences of the dental trauma are more severe (5).

Most of the patients with increased positive overjet are subjected to orthodontic treatment with fixed appliances during the childhood or adolescence $(5,6)$. There is some indication that tooth damage during a high speed frontal impact could be related to the type of orthodontic brackets (7). However, most studies focused on evaluating the bonding between the brackets and tooth structure and the consequences of debonding at the end of the treatment. Few studies evaluated the complex stress developments at the brackets and teeth during a frontal impact. Orofacial injuries can be prevented by wearing mouthguards $(6,8)$. Mouthguards are intraoral devices used to decrease the stress and strain generated during an impact and prevent dental injuries (9-11). Despite the recommendations that orthodontics patients participating in contact sports should wear a mouthguard to protect teeth and adjacent structures of oral-facial injuries, many patients disregard this important advice (12).

Special attention has been given to mouthguards for patients (specially athletes) undergoing active orthodontic treatment $(2,12)$. Orthodontic patients that are often practicing contact sports should receive a customfitted mouthguard provided by the orthodontist with an internal space for the brackets. The internal space in the mouthguard can be created with different materials and techniques, using wax, elastomeric materials or tube materials (13-15). The internal space is designed to maintain orthodontic biomechanics while wearing the mouthguard. Even with this internal space, stability and proper fit of a mouthguard in the oral cavity must be always be ensured because it is crucial for their proper functioning. Recommendations regarding mouthguard use for active orthodontics patients, biomechanical knowledge about fracture mechanisms, types of mouthguard materials, and methods of construction are necessary for more evidence-based practice (16). 
Several studies evaluated the biomechanical behavior of mouthguards and dental trauma $(11,17,18)$, however few studies evaluated the biomechanics of the dental trauma in orthodontics patients with increased positive overjet as well as the use of a mouthguard. Therefore, shock absorption mechanisms of mouthguards and stress distributions over tooth structures with bonded brackets are still unclear.

The aim of this study was to analyze the influence of orthodontic bracket presence, type (metallic or ceramic), and mouthguard presence on biomechanical response (stress and strain) during a frontal impact. The hypothesis tested was that there is no effect of the orthodontic bracket presence, type (metallic or ceramic), and mouthguard presence on the stress and strain generated during a frontal impact

\section{Material and Methods}

Two-Dimensional Dynamic Finite Element Impact Analysis

A patient with positive overjet was selected for this study with approval of the Ethics Committee (Protocol Number 58913316.7.0000.5145). The patient went through clinical examination in order to confirm the positive overjet and poor lip coverage (Fig. 1A, 1B and 1C). Cephalometric analysis was carried out to confirm the $6 \mathrm{~mm}$ overjet (Fig. 1D and $1 \mathrm{E})$. After the orthodontic appliance bonding procedure (Fig. 1F) the patient was immediately submitted to a Computed Tomography (CT) scan. A total of 704 slices were obtained with $23 \mathrm{~s}$ of acquisition and exposure parameters of $120 \mathrm{kV}$ and $3.0-7.0 \mathrm{~mA}$. Voxel dimensions were 0.125 $\mathrm{mm}$. After that, the patient also received an ethylene vinyl acetate (EVA) custom-fitted mouthguard (Fig. 1G). Using
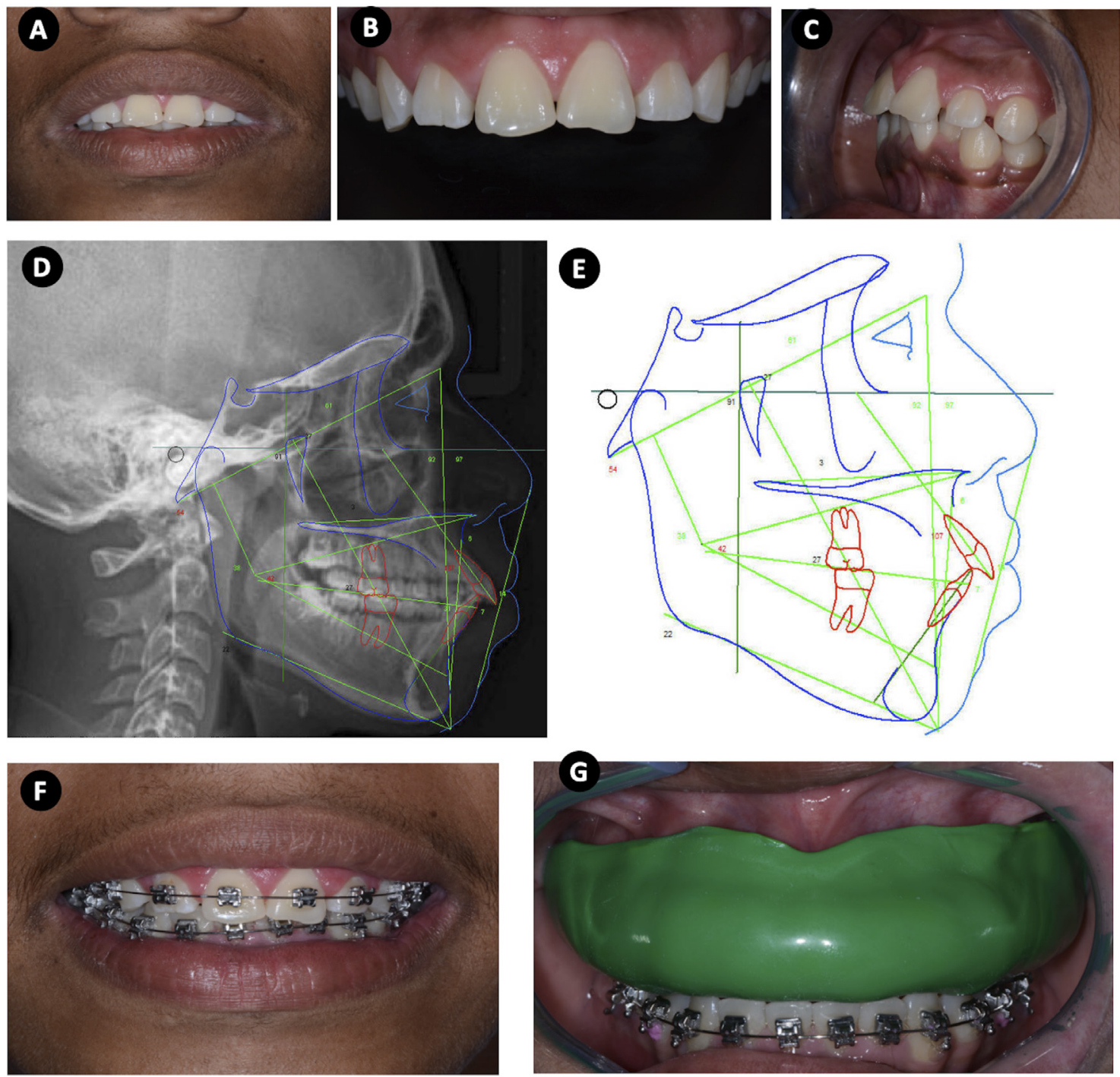

Figure 1. Patient with increased positive overjet selected for finite element impact analysis with and without the orthodontic appliance. A: Frontal view and poor lip coverage; B: Intra-oral view without the orthodontic appliance; C: Lateral view showing the increased positive overjet; D: Cephalometric radiograph; E: Cephalometric analysis to confirm the $6 \mathrm{~mm}$ overjet; F: Intraoral view with the orthodontic appliance installed; G: EVA custom-fitted mouthguard for an orthodontic patient. 
the CT scan from the selected patient, a two-dimensional image from the upper tooth (central incisor) was selected showing the periodontal ligament, bone support (cortical and trabecular bone), gingival tissue, orthodontic bracket and mouthguard (MTG) (Fig. 2A).

The cross-sectional image was exported to image analysis software (Image J, public domain, National Institute of Health, Bethesda, MD, USA) for tracing coordinates of the tissue outlines in the maxillary structures (Fig. 2B). The coordinates obtained were imported into a finite element analysis program (Marc/Mentat, MSC software, Santa Ana, CA, USA). Cubic-spline curves were drawn through these coordinates to recreate the tissue outlines (Fig. 2C). Five models were created for this study: Model without bracket and without MTG (Fig. 2D); Models with metallic bracket - MB (Fig. 2E and 2F); with ceramic bracket - CB (Fig. 2F); Models with metallic bracket and mouthguard (MB-MTG)
(Fig. 2G) and Models with ceramic bracket and mouthguard (CB-MTG) (Fig. 2H), following the methodology described by Verissimo et al.(10) Metallic and ceramic brackets had the same geometrical form but different mechanical properties. The mouthguard was created with $3 \mathrm{~mm}$ thickness. The element mesh was manually created using four-node isoparametric arbitrary quadrilateral plane strain elements with reduced integration (Fig. 2l). This type of element has a single integration point. Frictionless contact was prescribed between the mouthguard and the model interface. Nodal separation of the mouthguard from the tooth complex was allowed during the impact. All other interfaces were bonded. A dynamic impact analysis with a steel object ( 10 $\mathrm{mm}$ radius) moving at $1.0 \mathrm{~m} / \mathrm{s}$ initial velocity in horizontal direction was simulated (Fig. 2J). The rigid impact object simulated an impact with a rigid surface. The impact object hit the model and it bounces back to the original position.

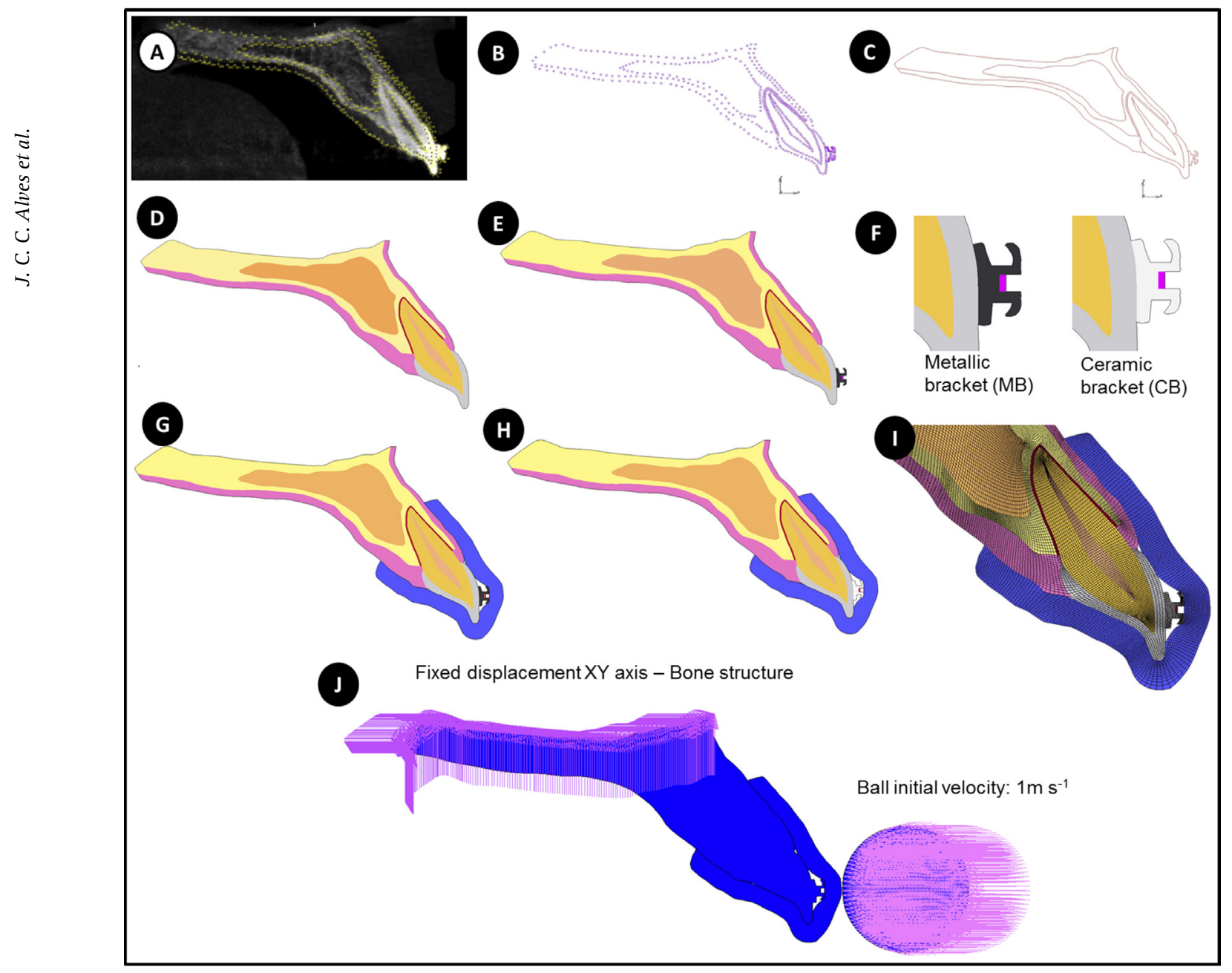

Figure 2. Generation of two-dimensional finite element models. A: maxillary central incisor CT-tomography image of the selected patient immediately after the orthodontic appliance installation; B: coordinates of the CT image imported from Image J; C: cubic-splines curves generated from the imported coordinates; D: model without bracket/without MTG; E: and F: model with metallic (MB) and ceramic bracket (CB); G: model with metallic bracket and mouthguard (MB-MTG); H: model with ceramic bracket and mouthguard (CB-MTG); I: finite element mesh distribution; $\mathrm{J}$ : boundary conditions. 
The impact object was also unrestrained after the initial velocity was applied. Gravitational forces were not modeled. Nodes on the base of the bone structure were rigidly fixed in the $X$ and $Y$ directions (Fig. 1J). All materials were considered linear-elastic, isotropic and homogeneous. The mechanical properties (elastic modulus - MPa E:, Poisson's ratio $(v)$ and material density $-\mathrm{g} / \mathrm{cm} 3 \mathrm{D}:)$ applied for the structures were: enamel (19): 84100, 0.30, 2.14; dentin (20): $18600,0.30,2.97$; periodontal ligament (21): 50, 0.45 , 0.95 ; trabecular bone (22): 1400, 0.31, 0.70; cortical bone (22): 13700, 0.33, 2.00; gingival tissue (23): $1.8,0.30,0.9$; EVA (10): $18.075,0.30,3.4$; steel (11) : 200000, 0.30, 7.8; polycristalline ceramic bracket (24): $380000,0.30,3.4$; metallic bracket (24): 210000, 0.30, 7.8.

Each model was solved in Marc. The results were recorded until the impact object lost contact with the enamel, bracket or mouthguard. A custom-made software subroutine collected the strain values in the $Y$ direction for one node on the palatal side. Mouthguard shock absorption ability (\%) was calculated defined as the percentage of strain compared to the peak strain value of the model without mouthguard and brackets (MB-MTG and CB-MTG). This subroutine also recorded the $10 \%$ highest stresses in the enamel and dentin during the impact. Stress distributions were analyzed for Von Mises equivalent stresses, which integrate all stress components into one stress equivalent value. To take into account that some materials are stronger in compression than in tension, Modified Von Mises stresses were also determined to show the significance of tensile stress components for models without mouthguard (25). The applied compressive and tensile strength values for enamel were 384.0 and $10.3 \mathrm{MPa}$ and for dentin 297.0 and $98.7 \mathrm{MPa}$, respectively (25).

\section{Results}

Von Mises stress distributions at the peak of impact are shown in Figure. 3. The mean of the 10\% highest stresses for enamel and dentin for the models during the impact analysis are shown in Fig. 4. Stresses for the model without bracket/without MTG (Fig. 3A) were concentrated at the buccal enamel and palatal surface. The models with MB and $C B$ concentrated higher stresses over a larger area at the impacted buccal enamel area (Fig. 3B and $3 \mathrm{C}$ ). The model with CB had the highest stress values (Fig. 4). In the dentin structure there was no substantial effect for the bracket presence/type (ceramic or metallic) (Fig. 4). For the models with mouthguard, the location of the stress concentrations changed to the root (Fig. $3 \mathrm{C}$ and

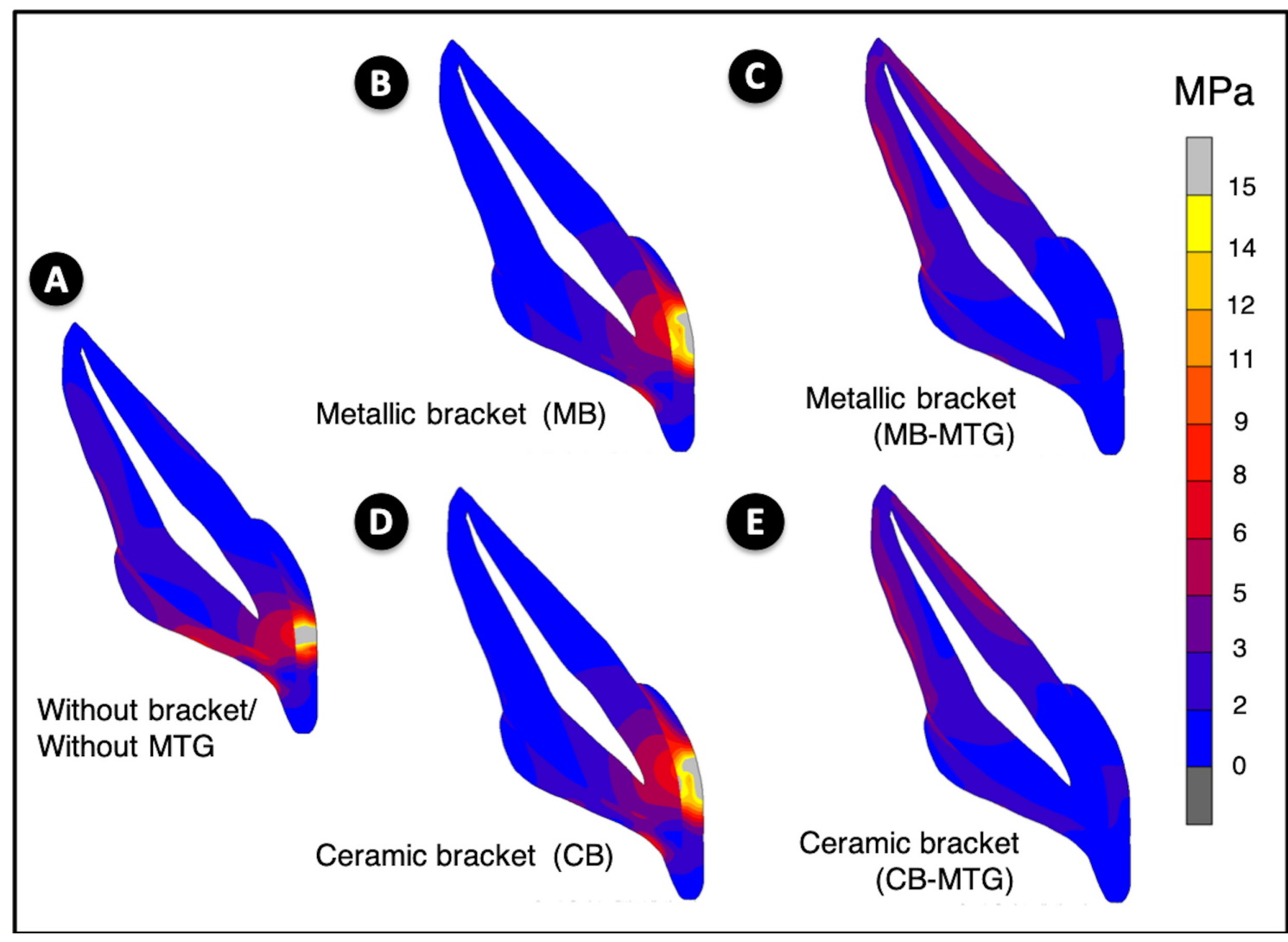

Figure 3. Von Mises stress distributions at the peak of the impact. A: model without bracket/ without MTG; B: metallic bracket (MB); C: metallic bracket with mouthguard (MB-MTG); D: ceramic bracket (CB); E: ceramic bracket with mouthguard (CB-MTG). 
4E). Lower stress values were found for the models with mouthguard compared to the models $\mathrm{MB}, \mathrm{CB}$ and without bracket/without MTG (Fig. 4).
Modified von Mises stress distributions at the peak of the impact, are shown in Figure 5. The models with metallic and ceramic brackets concentrated more tensile stresses at

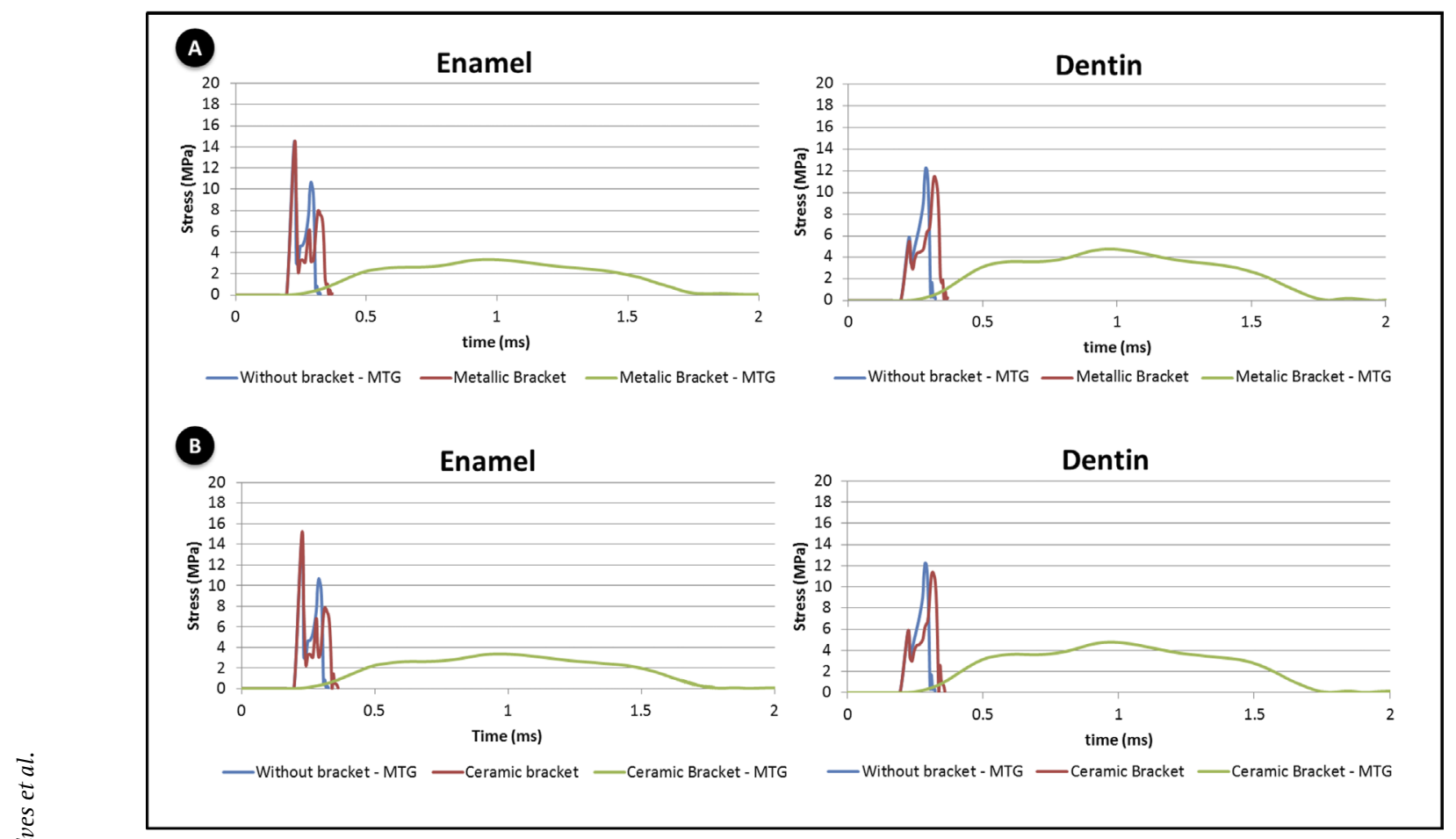

Figure 4. Mean of the 10\% highest stress values (Von Mises) for enamel and dentin during the impact. A: comparison between the models without bracket/without MTG, metallic bracket (MB) and metallic bracket with mouthguard (MB-MTG); B: comparison between the models without bracket/ without MTG, ceramic bracket (CB) and ceramic bracket with mouthguard (CB-MTG).

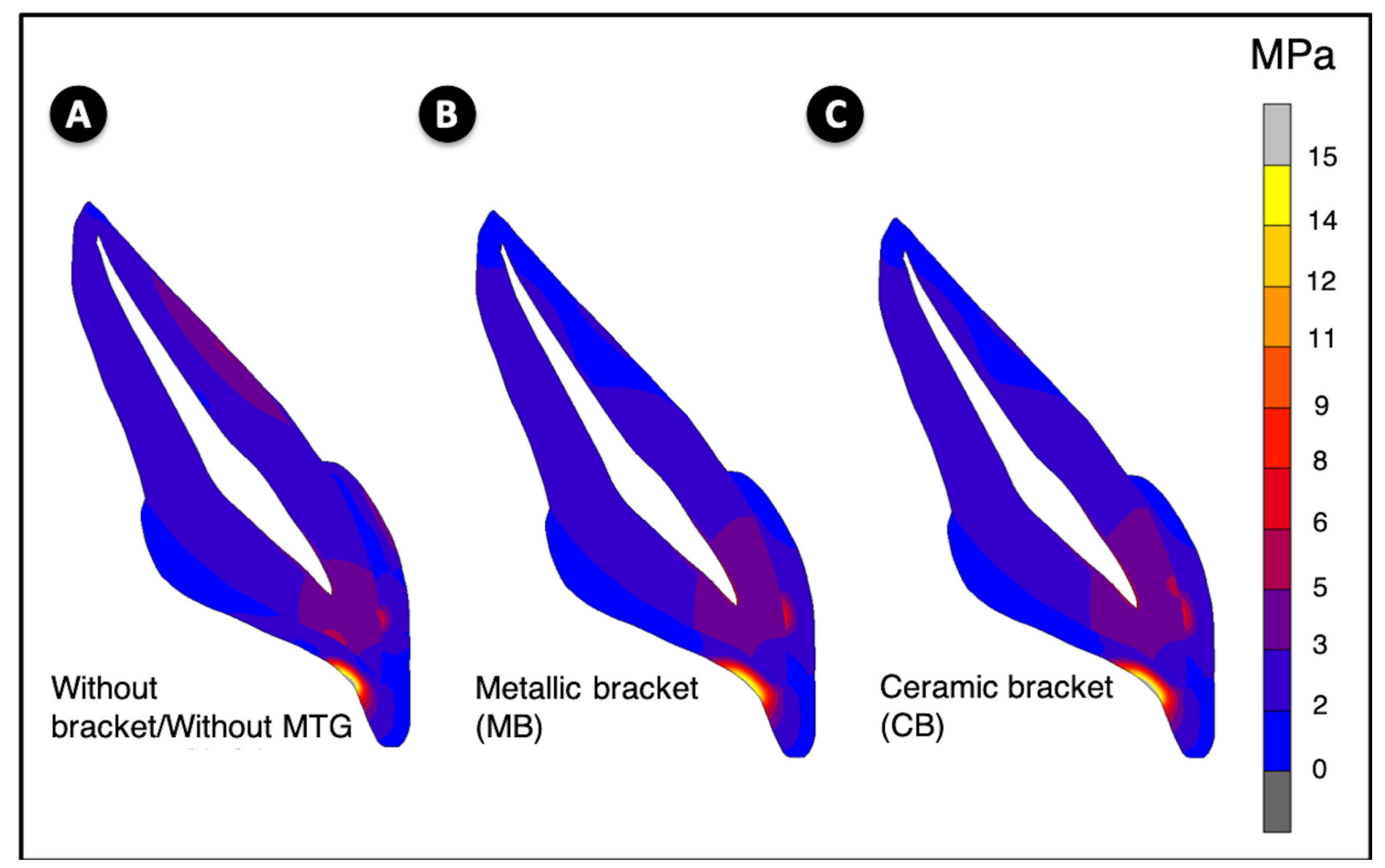

Figure 5. Modified Von Mises stress distributions at the peak of the impact for the models without mouthguard. A: without bracket/without MTG; B: metallic bracket (MB) and C: ceramic bracket (CB). 
the palatal surface and over a larger area. The model with ceramic bracket indicated more tensile stress (Fig. 5C). The history plot for the strain values during the impact collected on the palatal side of the tooth are shown in Fig. 6. Models without bracket/without MTG, CB and MB generated higher strain values. The model with a ceramic bracket exhibited higher strain values compared to the model with a metallic bracket. The time to reach the peak strain was longer for the MTG models. The mouthguard shock absorption capability values were $88.37 \%$ for the metallic bracket (Fig. $6 \mathrm{~A}$ ) and $89.27 \%$ for the ceramic bracket (Fig. 6B).

\section{Discussion}

Oral and facial traumas are common occurrences that affect people in deciduous, mixed and permanent dentition phases, often with severe aesthetic, functional, psychological and economic consequences. Some studies showed that patients with malocclusion carry more risks for dental and orofacial injuries (2). Increased positive overjet malocclusions are more prone to anterior trauma because of the anterior projection of the teeth and poor lip coverage $(5,6)$. Most of these conditions can be fully corrected by orthodontic treatment during childhood or adolescence (5). Some studies have reported that during the orthodontic treatment patients are also more susceptible to dental trauma and soft tissue traumas because of the bracket-wire presence $(3,4)$. There is no consensus in the literature that the bracket can potentiate or influence the stresses and strains generated in the teeth during an impact. There is also little information about mouthguard biomechanics for patients during orthodontic treatment. Therefore, this study tested the hypothesis that there is no effect of the orthodontic bracket presence, type (metallic or ceramic), and mouthguard presence on stresses and strains, shock absorption ability in a patient with increased positive overjet.

The hypothesis tested was rejected. The Von Mises stress distributions were affected by the presence and type of orthodontic brackets during impact with a rigid object (Fig. 3). The models with orthodontic brackets showed high stress levels at the enamel and buccal surface (Figs. 3B and 3D) over a larger area that may potentialize enamel fracture at the buccal region if the bracket still bonded after the impact. Theoretically, impact load can also cause debonding of the bracket, however we did not simulate debonding of the bracket. Further studies involved debonding should be carried out. On the other hand, the model without bracket

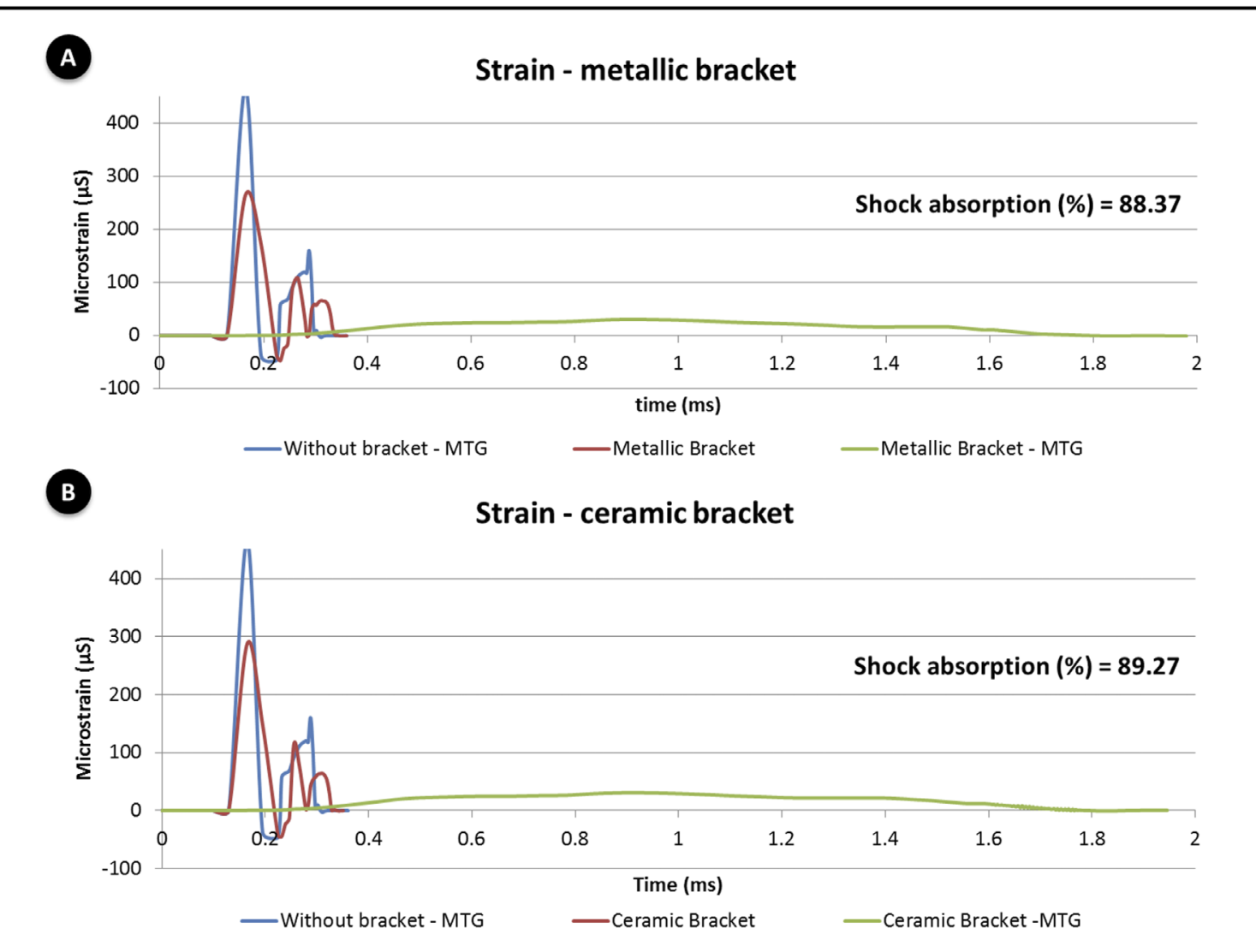

Figure 6. History plot for the strain values at the palatal side of the tooth and mouthguard shock absorption (\%). A: metallic bracket (MB) and $\mathrm{B}$ : ceramic bracket (CB). 
and without mouthguard concentrated higher stresses over a smaller area (punctual impact). Results of the strain showed slightly higher values for the dentin without bracket (Fig. 4) and suggested that punctual impact may be related with coronal enamel and dentin fracture because the stresses are more transmitted to the dentin. This can be also explained by the fact that the impact object hit different surfaces with same velocity (Larger area with bracket and smaller area without bracket). In this situation, the models with the orthodontic brackets (metallic or ceramic) will redistribute the stresses in a larger area of the enamel and may cause damage at the buccal enamel. Yapel and Quick evaluated the traumatic debonding of orthodontic brackets (metallic and ceramic) and they found that bracket debonding by impact forces presents a high risk of enamel damage at the buccal surface, which supports our Von Mises and Modified Von Mises stress results (7). The high stress concentrations on the buccal enamel can be related to the reported enamel damage during an impact. Stresses in the dentin structure were not affected by the orthodontic bracket, regardless of bracket type (Fig. 4). This can be explained by the distance between the impacted bracket and dentin structure. The enamel will have redistributed the impact forces before they

structure, especially in the enamel and particularly for the ceramic bracket. This can be explained by the higher elastic modulus of this bracket material that will transfer more of the initial impact energy to the enamel. Studies discussed that ceramic brackets, because of their brittle behavior, may offer some protection by shattering in front of an impact load (7). Bracket shattering was not modeled in this analysis. However, any advantageous impact energy dissipation it may offer depends on the shattering to happen before the impact stress peak has reached the enamel.

Finite element analysis was developed as an engineering tool to solve stress and strain conditions in complex structures. These stresses cannot be measured directly, and for failure in complex structures it is not easy to understand why and when a failure process is initiated. The relationship between stress and strain is expressed in constitutive equations according to universal physical laws. When dealing with physically and geometrically complex systems, an engineering concept that uses a numerical analysis to solve such equations becomes inevitable. Finite Element Analysis is a widely used numerical analysis that has been applied successfully in many engineering and bioengineering areas since the 1950s. This computational numerical analysis can be considered the most comprehensive method currently available to calculate the complex conditions of stress distributions as are encountered in dental systems. Dynamic finite element impact analysis was chosen for this study because they are different from more common static analysis where the force is applied so slowly that inertia can be ignored. This cannot be assumed for an impact analysis since at high loads such as the impact the velocity, acceleration and inertia forces generated cannot be neglected.

Mouthguards are intraoral devices made by Ethylene Vinyl Acetate (EVA) that can decrease the stress and strain in the tooth structure during impact and prevent dental trauma $(8,10,11)$. These devices are very important for sports practitioners who are under orthodontic treatment. Orthodontics societies and clinicians recommend that all orthodontic patients with fixed appliances wear mouthguards when playing contact sports. It is also recommended that these mouthguards are custom-fitted for their individual appliances. After the mouthguard fabrication, an orthodontist should check the fit and ensure that it does not interfere with the dental movements (12). Orthodontic clinicians who recommend the use of a mouthguard should consider a variety of factors, including the type of sport practiced, the type of malocclusion and overjet, the level and frequency of the game, previous history of trauma, and lip coverage (12). The current study indicated that the mouthguards reduced the stress and strain values in both enamel and dentin, regardless of the type of orthodontic brackets (Fig. 3C and $3 \mathrm{E})$. The EVA material of the mouthguards absorbed most of the impact deformation, which increased the time to absorb and redistribute the impact forces and thus decreased the stress and strain on the tooth structure (Fig. 6). The presence of a mouthguard thus allowed the impact stresses to be distributed through the dentin structures into the bone, which resulted in lower strain values at the palatal side of the crown. The mouthguard also reduced stresses between bracket and enamel, which can prevent the debonding or fracture of the orthodontic bracket itself, and thus not disrupt the orthodontic treatment. Therefore, considering the results of this finite element analysis, the use of the mouthguards during the contact sport practice (professional or amateur) should be considered for orthodontic active patients with fixed appliance.

It was observed that shock absorption ability was lower than $90 \%$. Verissimo et al reported levels for customfitted mouthguards shock absorption ability ranging from 95 to $98 \%$ based on finite element analysis studies and experimental impact tests of teeth without brackets.(911) The presence of the space created for the orthodontic bracket and the overjet condition thus slightly reduced the effectiveness of the mouthguard protection. It is obvious that a custom-fitted mouthguard made for a patient with orthodontic brackets has less retention and fit because the brackets should be isolated or fully covered during the 
impression procedure. This reaffirms that the orthodontist should always check the fit and adaptation of a mouthguard.

The results of our study showed that mouthguards can significantly decrease the stress and strain values in the teeth with fixed orthodontic appliances, either metallic or ceramic. Nowadays, with the high demand for aesthetics and well aligned teeth, aesthetic orthodontic appliances (sapphire, composite or ceramics) are ubiquitous. Therefore, it is crucial that the orthodontic clinician evaluates the risk of a patient for dental trauma, especially during sport practices, and indicate the use of a custom-fitted EVA mouthguard in order to decrease the risk of dental and orofacial injuries. Although the stress and strain results are straightforward and validated at the literature (9-11), twodimensional modeling have some geometric limitations and further research involving three-dimensional modeling should be considered.

It can be concluded that orthodontic bracket presence and type change the stress distributions and strain in teeth during impact. Ceramic brackets generated higher stress than metallic brackets. Mouthguards reduced the stresses and strains regardless of bracket composition.

\section{Resumo}

0 objetivo deste estudo foi analisar a influência da presença e tipo de bráquete ortodôntico (metálico ou cerâmico), e a presença de protetor bucal na resposta biomecânica durante impacto. Modelos bidimensionais em estado plano de deformação de paciente com incisivo central superior com overjet positivo acentuado foram criados baseados em tomografia computadorizada, simulando ligamento periodontal, suporte ósseo, tecido gengival, bráquetes ortodônticos (metálico e cerâmico) e o protetor bucal. Análise de elementos finitos não-linear de impacto foi realizada na qual uma esfera de aço atingiu o modelo a $1 \mathrm{~m} / \mathrm{s}$. A distribuição de tensões (Von Mises e Von Mises modificado) e a deformação foram avaliadas. As distribuições de tensões foram afetadas pela presença e tipo de bráquete. Modelos com bráquete metálico e cerâmico produziram maiores valores de tensões sobre maior área do esmalte vestibular. Modelos com bráquetes cerâmicos geraram maiores tensões do que metálicos. 0 protetor bucal reduziu as tensões e deformações geradas independentemente do tipo de bráquete. A capacidade de absorção de choques foi de 88.37 e $89.27 \%$ para os bráquetes metálicos e cerâmicos, respectivamente. A presença e o tipo de bráquete influenciou a distribuição de tensões e deformações durante o impacto. Bráquetes cerâmicos geraram maiores valores de tensão do que metálicos. Protetor bucal reduziu significativamente os picos de tensão e deformação.

\section{Acknowledgements}

This study was supported by grants from PAPE-UNIUBE and PIBIC-UNIUBE (Grant Number: 2016-030). The authors thank the Federal University of Uberlândia for the Finite Element Analysis laboratory support at the CP-BIO.

\section{References}

1. Sepet E, Aren G, Dogan Onur O, Pinar Erdem A, Kuru S, et al. Knowledge of sports participants about dental emergency procedures and the use of mouthguards. Dent Traumatol 2014;30:391-395.

2. Borzabadi-Farahani $A$, Borzabadi-Farahani $A$. The association between orthodontic treatment need and maxillary incisor trauma, a retrospective clinical study. Oral Surg Oral Med Oral Pathol Oral Radiol Endod 2011:112:e75-e80.

3. Chen DR, McGorray SP, Dolce C, Wheeler TT. Effect of early Class II treatment on the incidence of incisor trauma. Am J Orthod Dentofacial Orthop 2011;140:e155-160.

4. Koroluk LD, Tulloch JF, Phillips C. Incisor trauma and early treatment for Class II Division 1 malocclusion. Am J Orthod Dentofacial Orthop 2003;123:117-125.

5. Thiruvenkatachari B, Harrison J, Worthington H, O'Brien K. Early orthodontic treatment for Class II malocclusion reduces the chance of incisal trauma: Results of a Cochrane systematic review. Am J Orthod Dentofacial Orthop 2015;148:47-159.

6. Owtad P, Shastry S, Papademetriou M, Park JH. Management guidelines for traumatically injured teeth during orthodontic treatment. J Clin Pediatr Dent 2015;39:292-296.

7. Yapel MJ, Quick DC. Experimental traumatic debonding of orthodontic brackets. Angle Orthod 1994;64:131-136.

8. Newsome PR, Tran DC, Cooke MS. The role of the mouthguard in the prevention of sports-related dental injuries: a review. Int J Paediatr Dent 2001;11:396-404.

9. Verissimo C, Bicalho AA, Soares PB, Tantbirojn D, Versluis A, Soares CJ. The effect of antagonist tooth contact on the biomechanical response of custom-fitted mouthguards. Dent Traumatol 2017;33:57-63.

10. Verissimo C, Costa PV, Santos-Filho PC, Tantbirojn D, Versluis A, Soares CJ. Custom-Fitted EVA Mouthguards: what is the ideal thickness? a dynamic finite element impact study. Dent Traumatol 2016;32:95-102.

11. Verissimo C, Costa PV, Santos-Filho PC, Fernandes-Neto AJ, Tantbirojn $D$, et al. Evaluation of a dentoalveolar model for testing mouthguards: stress and strain analyses. Dent Traumatol 2016;32:4-13.

12. Bussell MA, Barreto LS. The recommendation and provision of mouthguards: a survey of consultant orthodontists in the UK. J Orthod 2014;41:141-146.

13. Maeda Y, Matsuda S, Tsugawa T, Maeda S. A modified method of mouthguard fabrication for orthodontic patients. Dent Traumatol 2008;24:475-478.

14. Pacheco G, Clemente MP, Vasconcelos M, Ferreira AP. The orthodontic sports protection appliance. J Clin Orthod 2010;44:41-4;6.

15. Croll TP, Castaldi CR. Custom sports mouthguard modified for orthodontic patients and children in the transitional dentition. Pediatr Dent 2004;26:417-420.

16. Fields HW, Christensen JR. Orthodontic procedures after trauma. Pediatr Dent 2013;35:175-183.

17. Bhalla A, Grewal N, Tiwari U, Mishra V, Mehla NS, Raviprakash S, et al. Shock absorption ability of laminate mouth guards in two different malocclusions using fiber Bragg grating (FBG) sensor. Dent Traumatol 2013;29:218-225.

18. Ozawa T, Takeda $T$, Ishigami $K_{1}$ Narimatsu $K_{1}$ Hasegawa $K_{1}$ Nakajima $K_{\text {, et }}$ al. Shock absorption ability of mouthguard against forceful, traumatic mandibular closure. Dent Traumatol 2014;30:204-210.

19. Zarone $F$, Sorrentino $R$, Apicella D, Valentino B, Ferrari M, Aversa R, Apicella A. Evaluation of the biomechanical behavior of maxillary central incisors restored by means of endocrowns compared to a natural tooth: a 3D static linear finite elements analysis. Dent Mater 2006;22:1035-1044.

20. Sano $H$, Ciucchi B, Matthews WG, Pashley DH. Tensile properties of mineralized and demineralized human and bovine dentin. J Dent Res 1994;73:1205-1211.

21. Rees JS, Jacobsen PH. Elastic modulus of the periodontal ligament. Biomaterials 1997;18:995-999.

22. Carter DR, Hayes WC. Compact bone fatigue damage--I. Residual strength and stiffness. J Biomech 1977;10:325-337.

23. Holberg C, Heine AK, Geis P, Schwenzer K, Rudzki-Janson I. Threedimensional soft tissue prediction using finite elements. Part II: Clinical application. J Orofac Orthop 2005;66:122-134.

24. Elsaka SE, Hammad SM, Ibrahim NF. Evaluation of stresses developed in different bracket-cement-enamel systems using finite element analysis with in vitro bond strength tests. Prog Orthod 2014;15:33.

25. Versluis A, Versluis-Tantbirojn D. Filling cavities or restoring teeth? J Tenn Dent Assoc 2011;91:36-42;quiz-3.

Received March 11, 2020 Accepted August 25, 2020 